\title{
Morphometric profile in foetuses and evolution of Achilles tendon
}

\author{
A. Waśniewska ${ }^{1}$, Ł. Olewnik² ${ }^{2}$ M. Polguj ${ }^{1}$ \\ 'Department of Normal and Clinical Anatomy, Chair of Anatomy and Histology, Medical University of Lodz, Poland \\ 2Department of Anatomical Dissection and Donation, Chair of Anatomy and Histology, Medical University of Lodz, Poland
}

[Received: 10 November 2020; Accepted: 28 December 2020; Early publication date: 9 February 2021]

\begin{abstract}
Background: The Achilles tendon (AT) develops from the merge of the tendinous part of the gastrocnemius (GM) and soleus (SM) muscles. The AT is the structural base for the biomechanical work of the ankle joint. Understanding morphometry of the AT is crucial due to the tendon vulnerability to rupture and damage which requires further surgical repair and management. Despite its clinical significance, data concerning measurements of the AT in human foetuses are scare. The aim of our study was to assess the AT, GM and SM morphometry in human foetuses. Materials and methods: Thirty-seven spontaneously-aborted human foetuses (17 male, 20 female) aged 18-38 weeks of gestation were examined. The morphometry of the GM, SM and AT were evaluated.

Results: No significant correlation between sex or side and size of the AT in human foetuses was observed. The only significant correlation was between sex and the length of the tendon of the SM; in $3^{\text {rd }}$ trimester it was longer in male than in female. In $2^{\text {nd }}$ trimester the SM muscle to tendon ratio was higher in female than in male.

Conclusions: There was no significant correlation between sex or side and size of the AT in human foetuses, probably due to scant muscle load during prenatal period. (Folia Morphol 2022; 81, 1: 144-149)
\end{abstract}

Key words: foetuses, Achilles tendon, calcaneal tendon, triceps suralis

\section{INTRODUCTION}

The Achilles tendon (AT), also known as calcaneal tendon, is the largest and the strongest tendon in human body $[9,14,23]$. The AT develops from the merge of the tendinous part of the gastrocnemius muscle (GM) and soleus muscle (SM) $[2,5,9]$. The GM and SM, that is beneath the GM, componentize the triceps surae or "calf" muscle [5, 7]. The triceps surae and the AT belong to superficial compartment of the calf [14]. The GM is composed of two heads, the medial and lateral. The medial head originates from the medial supracondylar line and adductor tubercle of the femur, and the lateral head originates from the posterior part of the lateral femoral condyle, posterior and superior to the lateral epicondyle [5]. The lateral head is smaller, shorter and extends in lesser degree than the medial head $[5,25]$. The SM originates from the soleal line and the middle part of the border of the tibia, from the posterior surface of the head and proximal part of the shaft of the fibula, and from a fibrous band between these two bones [25]. The AT is supplied by the posterior tibial artery, the peroneal arteries and the tibial nerve [14]. The AT inserts to the calcaneal tuberosity, to its posterior-superior aspect $[11,26]$.

Address for correspondence: Dr. A. Waśniewska, Department of Normal and Clinical Anatomy, Chair of Anatomy and Histology, Medical University of Lodz, ul. Żeligowskiego 7/9, 90-752 Łódź, Poland, e-mail: ania.wasniewska@gmail.com

This article is available in open access under Creative Common Attribution-Non-Commercial-No Derivatives 4.0 International (CC BY-NC-ND 4.0) license, allowing to download articles and share them with others as long as they credit the authors and the publisher, but without permission to change them in any way or use them commercially. 
The AT is the structural base for the biomechanical work of the ankle joint [28]. The GM with the SM is the main plantar flexor of the ankle joint $[14,24]$. The SM is also a powerful knee flexor [21]. It is not able to exert full power at both joints simultaneously, for example when the knee is flexed; GM is unable to generate as much force at the ankle [21]. The opposite is true when the ankle is flexed.

Multiple morphological variations were described in this area, whereas most of them concerns plantaris muscle, GM and SM, especially their attachments, number of heads or even presence $[17,20,21]$.

Increasing interest in sport activity results in increasing number of tendon injuries [9]. Problems with tendons are dominated by the AT, among athletes as well as the general public $[9,11,28]$. Disorders of the AT might be traumatic and nontraumatic, e.g. tendinopathy, ruptures of the tendon and insertional tendinitis $[18,29,30]$. Congenital disorders of the AT may result in toe walking or equinus deformation in children [8]. Understanding morphometry of the AT is crucial due to the tendon vulnerability to rupture and damage which requires further surgical repair and management [11]. Previous studies compared the measurements of the AT i.a. between sexes or sides in adults and proposed that differences were more correlated with the muscle strength, rather than gender [13]. Despite its clinical significance, data concerns measurements of the AT in human foetuses are scare.

The aim of our study was to assess the AT, GM and SM morphometry in human foetuses. We hypothesize that there will not be significant correlation between sex or side and size of the AT in human foetuses because of scant muscle load during prenatal period.

\section{MATERIALS AND METHODS}

Thirty-seven spontaneously-aborted human foetuses (17 male, 20 female) aged 18-38 weeks of gestation were examined. The foetuses were obtained from spontaneous abortion after parental consent. The study was conducted in accordance with the cadaveric donation programme for both adults and foetuses and with the legal procedures in force in Poland. Their ages were determined on the basis of cranio-sacral and head measurements. Foetuses were divided into two groups according to trimester. Permission for the study was received from the Local Bioethic Committee (agreement no. RNN/218/20/KE).
Table 1. Detail measurements of muscles and tendon

\begin{tabular}{|c|c|}
\hline Structure & Measurements \\
\hline \multirow[t]{4}{*}{$\begin{array}{l}\text { Gastrocnemius } \\
\text { muscle }\end{array}$} & $\begin{array}{l}\text { Length of the lateral head - distance from posterior } \\
\text { part of the lateral femoral condyle to the end of its } \\
\text { muscle part }\end{array}$ \\
\hline & $\begin{array}{l}\text { Length of the medial head — distance from poste- } \\
\text { rior part of the medial femoral condyle to the end of } \\
\text { its muscle part }\end{array}$ \\
\hline & $\begin{array}{l}\text { Length of the lateral tendon-distance from the } \\
\text { end of its muscle part to the calcaneal tuberosity }\end{array}$ \\
\hline & $\begin{array}{l}\text { Length of the medial tendon - distance from the } \\
\text { end of its muscle part to the calcaneal tuberosity }\end{array}$ \\
\hline \multirow[t]{2}{*}{ Soleus muscle } & $\begin{array}{l}\text { Length from its beginning at soleal line on tibia to the } \\
\text { end of the muscle part }\end{array}$ \\
\hline & $\begin{array}{l}\text { Length of the tendon from the end of its muscle part } \\
\text { to the calcaneal tuberosity }\end{array}$ \\
\hline \multirow[t]{2}{*}{ Achilles tendon } & Width at the calcaneal tuberosity \\
\hline & Thickness at the calcaneal tuberosity \\
\hline
\end{tabular}

A dissection of the leg and foot was performed by traditional techniques $[15,16,18,19]$. Firstly $G M$ was exposed by the subcutaneous tissue. Morphometric measurements of the lateral and medial head and the tendon of the GM were performed. Secondly GM was separated from the SM, then measurements of the muscle and tendon of the SM were performed. The thickness and width of the AT was measured at its insert to calcaneal tuberosity. Detailed measurements are characterized in Table 1 and Figure 1. Measurements were carried out with an electronic digital calliper (Mitutoyo Corporation, Kawasaki-shi, Kanagawa, Japan). Each measurement was performed twice with an accuracy of up to $0.01 \mathrm{~mm}$.

\section{Ethical approval and consent to participate}

The cadavers belonged to the Department of Anatomical Dissection and Donation, Medical University of Lodz.

\section{Statistical analysis}

The collected measurements of muscles and tendon were compared using the Statistica 13.1 software package (StatSoft, Cracow, Poland). The Mann-Whitney $U$ test and the $\chi^{2}$ test were used to compare nominal and contentious variables between two groups; the Shapiro-Wilk test was used to determine the normality of the distribution. The level of significance was 0.05 .

\section{RESULTS}

The mean length of medial head of GM was longer than lateral head in both second and third trimester 


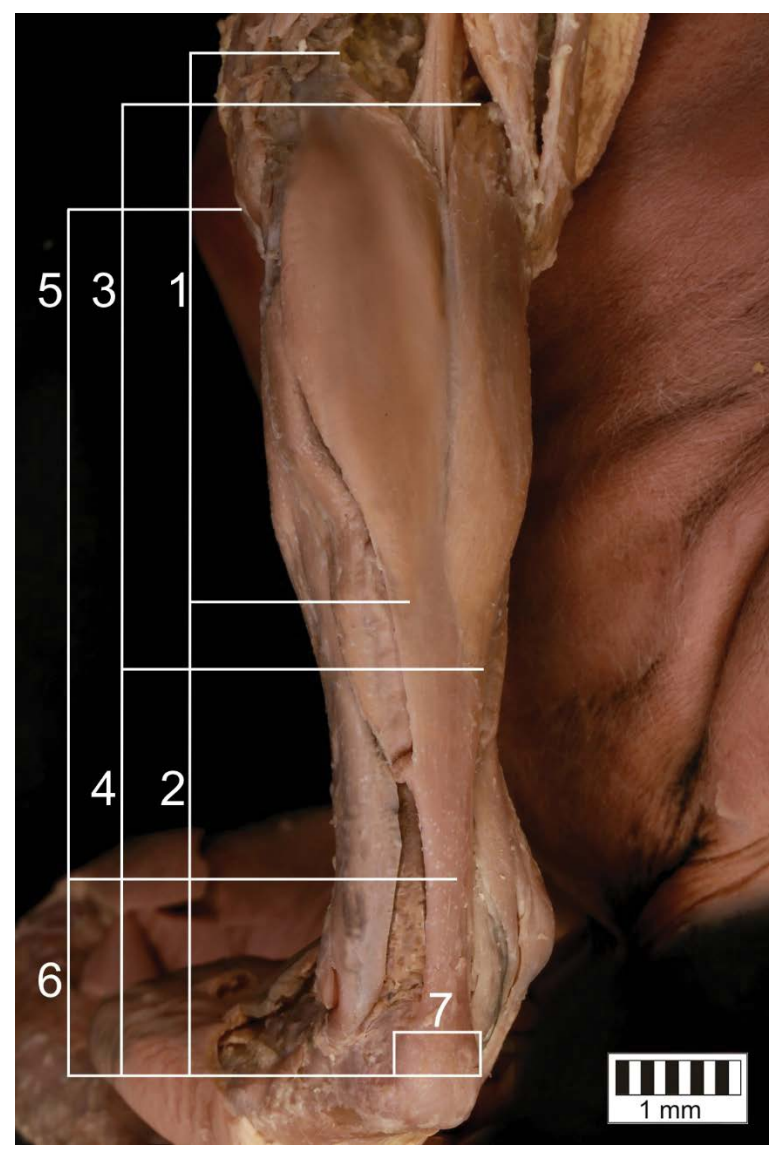

Figure 1. Detail measurements of muscles and tendon; 1 - length of the lateral head of the gastrocnemius muscle (GM); 2 - length of the lateral tendon of the $\mathrm{GM} ; 3$ - length of the medial head of the GM; 4 - length of the medial tendon of the GM; 5 - length of the muscle of the soleus muscle (SM); 6 - length of the tendon of the SM; 7 - thickness and width of the Achilles tendon.

( $27.33 \pm 6.04 \mathrm{~mm}$ vs. $29.46 \pm 5.95 \mathrm{~mm}, \mathrm{p}=0.049$; $45.84 \pm 5.85 \mathrm{~mm}$ vs. $40.47 \pm 5.9 \mathrm{~mm}, \mathrm{p}=0.036$, respectively). The mean length of the tendon of the medial part of the GM was shorter than lateral part; however, statistical difference was observed only in second trimester of the gestation (second trimester: $24.92 \pm$ $\pm 4.48 \mathrm{~mm}$ vs. $27.93 \pm 4.29 \mathrm{~mm}, \mathrm{p}<0.001$; third trimester: $42.22 \pm 10.05 \mathrm{~mm}$ vs. $48.64 \pm 90.1 \mathrm{~mm}$, $p=0,113)$. In third trimester the mean length of muscle part of soleus was longer in male than in female, $62.98 \pm 13.14 \mathrm{~mm}$ and $53.57 \pm 2.57 \mathrm{~mm}$, respectively. The mean length of tendon of SM in third trimester was also longer in male $(24.83 \pm 3.42 \mathrm{~mm})$ than in female $(18.95 \pm 2.36 \mathrm{~mm})$, what was significant, $p=0.045$. The mean width and thickness of the AT was larger in male than in female in third trimester. The mean width and thickness of the AT in male was $8.26 \pm 1.94 \mathrm{~mm}$ and $1.46 \pm 0.28 \mathrm{~mm}$,

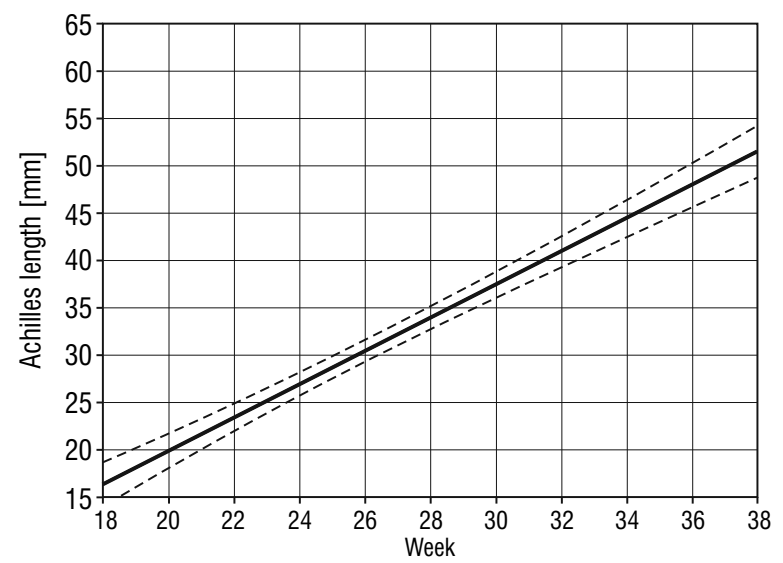

Figure 2. Linear correlation between length of the Achilles tendon and week of gestation with $95 \%$ confidence interval.

in female $7.38 \pm 0.31 \mathrm{~mm}$ and $1.33 \pm 0.05 \mathrm{~mm}$ respectively. However in second trimester the mean width of the AT was larger in female $(5.01 \pm 1.5 \mathrm{~mm})$ than in male $(4.81 \pm 1.12 \mathrm{~mm})$. The mean thickness of the AT in second trimester was larger in male $(1.07 \pm 0.46 \mathrm{~mm})$ than in female $(1.01 \pm 0.43 \mathrm{~mm})$. In second trimester, the muscle to tendon ratio of the SM was significantly higher in female $(2.75 \pm 0.76 \mathrm{~mm})$ than in male $(2.29 \pm 0.77 \mathrm{~mm}), \mathrm{p}=0.029$. The detailed analyses of the performed measurements are presented in Figure 2 and Tables 2 and 3.

\section{DISCUSSION}

To best of our knowledge our investigation is the first study to analyse morphometric measurements of the AT in such numerous group of human foetuses, what may be useful as a basic research for future studies concerning the AT. The key result of our study was that there is no significant correlation between sex or side and size of the AT in human foetuses. The only significant correlation was between sex and the length of the tendon of the SM; in third trimester it was longer in male than in female ( $p=0.045)$. In second trimester the SM muscle to tendon ratio was higher in female than in male $(p=0.029)$.

In order to understand the differences in the structure of such a complex tendon, it is necessary to understand the basics of embryology. In an $11 \mathrm{~mm}$ embryo the common flexor mass begins to show signs of differentiation into the muscle rudiments $[3,6]$. In a $14 \mathrm{~mm}$ embryo the two muscle groups are fairly distinct: a superficial, proximolateral group for the GM SM, and plantaris muscle, and a deep, more medial group for the flexor hallucis longus, 
Table 2. Measurements of the Achilles tendon, gastrocnemius muscle (GM) and soleus muscle (SM) in third trimester foetuses

\begin{tabular}{|c|c|c|c|c|c|c|}
\hline \multirow[t]{2}{*}{ Features (third trimester) } & \multicolumn{3}{|c|}{ Sex } & \multicolumn{3}{|c|}{ Body side } \\
\hline & Male $(n=10)$ & Female $(\mathbf{n}=2)$ & $\mathbf{P}$ & Left $(n=6)$ & Right $(\mathrm{n}=6)$ & $\mathbf{P}$ \\
\hline \multicolumn{7}{|l|}{ GM: } \\
\hline LH muscle & $41.61 \pm 5.77$ & $34.81 \pm 2.54$ & 0.144 & $39.57 \pm 3.59$ & $41.38 \pm 7.85$ & 0.619 \\
\hline LH tendon & $49.58 \pm 9.44$ & $43.98 \pm 6.18$ & 0.449 & $48 \pm 10.36$ & $49.28 \pm 8.38$ & 0.818 \\
\hline MH muscle & $46.38 \pm 6.3$ & $43.12 \pm 1.12$ & 0.498 & $44.12 \pm 4.72$ & $47.56 \pm 6.78$ & 0.331 \\
\hline MH tendon & $44.24 \pm 9.75$ & $32.13 \pm 3.22$ & 0.124 & $43.39 \pm 10.76$ & $41.05 \pm 10.14$ & 0.706 \\
\hline \multicolumn{7}{|l|}{ SM: } \\
\hline Muscle & $62.98 \pm 13.14$ & $53.57 \pm 2.57$ & 0.354 & $59.68 \pm 12.54$ & $63.14 \pm 13.31$ & 0.652 \\
\hline Tendon & $24.83 \pm 3.42$ & $18.95 \pm 2.36$ & 0.045 & $25.2 \pm 4.32$ & $22.50 \pm 3.26$ & 0.251 \\
\hline \multicolumn{7}{|l|}{ Achilles: } \\
\hline Width & $8.26 \pm 1.94$ & $7.38 \pm 0.31$ & 0.551 & $7.98 \pm 2.06$ & $8.24 \pm 1.65$ & 0.817 \\
\hline Thickness & $1.46 \pm 0.28$ & $1.33 \pm 0.05$ & 0.559 & $1.47 \pm 0.29$ & $1.4 \pm 0.25$ & 0.639 \\
\hline GM LH to MH muscle & $0.9 \pm 0.07$ & $0.81 \pm 0.08$ & 0.141 & $0.89 \pm 0.04$ & $0.87 \pm 0.11$ & 0.559 \\
\hline GM LH muscle to tendon ratio & $0.86 \pm 0.12$ & $0.80 \pm 0.17$ & 0.615 & $0.85 \pm 0.13$ & $0.85 \pm 0.14$ & 0.983 \\
\hline GM MH muscle to tendon ratio & $1.08 \pm 0.18$ & $1.35 \pm 0.17$ & 0.075 & $1.05 \pm 0.18$ & $1.19 \pm 0.20$ & 0.231 \\
\hline SM muscle to tendon ratio & $2.6 \pm 0.73$ & $2.86 \pm 0.49$ & 0.650 & $2.42 \pm 0.66$ & $2.86 \pm 0.69$ & 0.281 \\
\hline
\end{tabular}

$\mathrm{LH}$ - lateral head of gastrocnemius; $\mathrm{MH}$ - medial head of gastrocnemius

Table 3. Measurements of the Achilles tendon, gastrocnemius muscle (GM) and soleus muscle (SM) in second trimester foetuses

\begin{tabular}{|c|c|c|c|c|c|c|}
\hline \multirow[t]{2}{*}{ Features (second trimester) } & \multicolumn{3}{|c|}{ Sex } & \multicolumn{3}{|c|}{ Body side } \\
\hline & Male (n = 24) & Female $(\mathrm{n}=38)$ & $\mathbf{P}$ & Left $(n=31)$ & Right ( $n=31$ ) & $\mathbf{P}$ \\
\hline \multicolumn{7}{|l|}{ GM: } \\
\hline LH muscle & $26.12 \pm 4.97$ & $28.07 \pm 6.55$ & 0.225 & $27.04 \pm 5.31$ & $27.61 \pm 6.75$ & 0.718 \\
\hline LH tendon & $27.22 \pm 3.86$ & $28.36 \pm 4.53$ & 0.318 & $28.06 \pm 4.16$ & $27.80 \pm 4.47$ & 0.812 \\
\hline MH muscle & $28.35 \pm 5.42$ & $30.13 \pm 6.22$ & 0.26 & $29.84 \pm 5.37$ & $29.09 \pm 6.53$ & 0.625 \\
\hline MH tendon & $23.99 \pm 3.42$ & $25.48 \pm 4.97$ & 0.212 & $24.86 \pm 4.57$ & $24.97 \pm 4.46$ & 0.921 \\
\hline \multicolumn{7}{|l|}{ SM: } \\
\hline Muscle & $34.77 \pm 5.44$ & $37.24 \pm 6.61$ & 0.137 & $36.31 \pm 6.30$ & $36.31 \pm 6.33$ & 0.999 \\
\hline Tendon & $16.3 \pm 4.17$ & $14.43 \pm 4.19$ & 0.096 & $14.72 \pm 4.02$ & $15.53 \pm 4.48$ & 0.465 \\
\hline \multicolumn{7}{|l|}{ Achilles: } \\
\hline Width & $4.81 \pm 1.12$ & $5.01 \pm 1.5$ & 0.586 & $4.87 \pm 1.41$ & $4.99 \pm 1.34$ & 0.734 \\
\hline Thickness & $1.07 \pm 0.46$ & $1.01 \pm 0.43$ & 0.622 & $0.95 \pm 0.43$ & $1.11 \pm 0.44$ & 0.170 \\
\hline GM LH to MH muscle & $0.93 \pm 0.15$ & $0.94 \pm 0.15$ & 0.891 & $0.91 \pm 0.08$ & $0.96 \pm 0.19$ & 0.150 \\
\hline GM LH muscle to tendon ratio & $0.96 \pm 0.17$ & $1.01 \pm 0.29$ & 0.579 & $0.96 \pm 0.15$ & $1.01 \pm 0.33$ & 0.489 \\
\hline GM MH muscle to tendon ratio & $1.19 \pm 0.26$ & $1.21 \pm 0.27$ & 0.889 & $1.22 \pm 0.23$ & $1.18 \pm 0.29$ & 0.587 \\
\hline SM muscle to tendon ratio & $2.29 \pm 0.77$ & $2.75 \pm 0.76$ & 0.029 & $2.61 \pm 0.7$ & $2.54 \pm 0.88$ & 0.734 \\
\hline
\end{tabular}

LH — lateral head of gastrocnemius; $\mathrm{MH}$ - medial head of gastrocnemius

flexor digitorum longus and popliteus, and tibialis posterior [3,6]. The gastrocnemius group is connected with the blastema of the calcaneus and the two long flexor muscles with the flat aponeurotic "footplate" from which tendons extend to the blastema of the digits $[3,6]$. The gastrocnemius-soleus group gradually spreads from its original lateral position towards the medial side of the leg to attain the tibial attachment, and the two heads of the GM develop during the second half of the second month, the 
medial head attaining its attachment later than the lateral $[3,6]$. The plantaris muscle seems to split off at a comparatively late stage from the lateral head of the GM $[3,6]$.

From an evolutionary point of view, the difference between morphology of the triceps surae in human and the other species is apparent [1]. Humans' bellies of GM are short, their tendon fuse with SM tendon and develop massive AT [1]. In herbivorous apes, the AT is absent or very short, thus their muscles of posterior leg extended to their tarsal bones [12]. Changes in lifestyle, like food supply, forced apes to adapt to this situation and evolve their anatomy [12]. Differences in food intake, correlate with differences in locomotion [1]. Gorillas, orangutans, bonobos and chimpanzees share a wide range of locomotor behaviours such as clambering and orthograde suspension, quadrupedalism, whereas modern humans are primarily bipeds $[1,7]$. The longer ATs were observed in early hominis than in apes [12]. The key role in development of the AT was in fast locomotion, e.g. hunting, that is why the AT is more evolutionary advantage in athletes [12].

In Pang and Yings' [22] sonographic study, the cross sectional area of the AT was significantly higher in 50-year-old and older patients than in younger patients. Furthermore, in that study, the cross-sectional area of the AT in the dominant leg was significantly higher than that in the nondominant leg [22]. Also Ying et al. [31] noticed that the thickness of the AT for dominant leg in the both regularly exercise group and the irregularly exercise group, is significantly higher than in the nondominant leg. Moreover, in their study, the mean thickness of the AT in the regularly exercise group was significantly higher in comparison with the irregularly exercise group [31]. Previous studies noted that differences in mechanical properties of the AT between male and female is more correlated with the differences in muscle strength, rather than sex [13]. Probably due to that there were no significant differences in thickness or width of the AT between sexes or body sides in our research; the use of muscle in foetuses is minimal.

The medial head of the GM dominate in size and power over lateral head $[5,25]$. This superiority of medial belly was also visible in our measurements. Kearns et al. [10] examined soccer players and compared them with moderate active and untrained college students. The thickness of the medial head of the GM of the dominant leg was significantly larger in the soccer players than in others [10]. However, in our study, there was no positive correlation between muscle size and body side or sex. It might be also the result of the low muscle load in human foetuses.

Although the AT is the most powerful tendon in human body $[9,14,23]$, it is very vulnerable to injuries $[12,28]$. The "Achilles tendinitis" has formerly been used for describing any pain in the posterior region; however, nowadays vocabulary of disorders in this region of leg is more miscellaneous and precise [26]. We can differentiate inflammation of the AT with its adjacent structures, such as: paratenonitis, tendonitis and bursitis $[18,26,29,30]$. Tendinosis, that is another AT disorder, is a noninflammatory process caused by fatty or mucinoid degeneration with a disorganisation in collagen structure $[4,26]$. Ball or racquet sports or other athletic activity has been noted as a cause of the AT rupture up to $80 \%$ of cases $[26,27]$. The high proneness of the AT, despite its enlargement, may raise us a question, what is the future of the AT? How thick, long and wide it will be in our descendants? Will it endure in its shape?

The present study does have some limitations. First of all, no sample size calculation was performed. Moreover, the abundance of group according to sex was not equal. However, the number of the human foetuses in our research was larger in comparison with previous studies.

\section{CONCLUSIONS}

There was no significant correlation between sex or side and size of the AT in human foetuses, probably due to scant muscle load during prenatal period. However, we still do not know how important is genetics and environment regarding the aetiopathology of the disorders of the AT. The vulnerability of the AT to injuries should motivate our efforts in carrying out research to better understand its complicated pathology and increase the effectiveness of its treatments.

\section{Conflict of interest: None declared}

\section{REFERENCES}

1. Aerts $P, D^{\prime}$ Août $K$, Thorpe $S$, et al. The gibbon's Achilles tendon revisited: consequences for the evolution of the great apes? Proc Biol Sci. 2018; 285(1880), doi: 10.1098/ rspb.2018.0859, indexed in Pubmed: 29899076.

2. Ballal MS, Walker CR, Molloy AP. The anatomical footprint of the Achilles tendon: a cadaveric study. Bone Joint J. 2014; 96-B(10): 1344-1348, doi: 10.1302/0301-620X.96B10.33771, indexed in Pubmed: 25274919 . 
3. Boyle E, Mahon V, Diogo R. Muscles lost in our adult primate ancestors still imprint in us: on muscle evolution, development, variations, and pathologies. Curr Mol Biol Rep. 2020; 6(2): 32-50, doi: 10.1007/s40610020-00128-x.

4. Calleja M, Connell DA. The Achilles tendon. Semin Musculoskelet Radiol. 2010; 14(3): 307-322, doi: 10.1055/s0030-1254520, indexed in Pubmed: 20539956.

5. Dayton P. Anatomic, vascular, and mechanical overview of the achilles tendon. Clin Podiatr Med Surg. 2017; 34(2): 107-113, doi: 10.1016/j.cpm.2016.10.002, indexed in Pubmed: 28257668.

6. Diogo R, Siomava N, Gitton Y. Development of human limb muscles based on whole-mount immunostaining and the links between ontogeny and evolution. Development. 2019; 146(20), doi: 10.1242/dev.180349, indexed in Pubmed: 31575609.

7. Ferrero EM, Pastor JF, De Paz FF. Primates: Classification, Evolution and Behavior. In: Hughes E, Hill M (eds). Nova Science Publishers 2012: 1-70.

8. Gourdine-Shaw MC, Lamm BM, Herzenberg JE, et al. Equinus deformity in the pediatric patient: causes, evaluation, and management. Clin Podiatr Med Surg. 2010; 27(1): 25-42, doi: 10.1016/j.cpm.2009.10.003, indexed in Pubmed: 19963168.

9. Järvinen TAH, Kannus P, Maffulli N, et al. Achilles tendon disorders: etiology and epidemiology. Foot Ankle Clin. 2005; 10(2): 255-266, doi: 10.1016/j.fcl.2005.01.013, indexed in Pubmed: 15922917.

10. Kearns CF, Isokawa M, Abe T. Architectural characteristics of dominant leg muscles in junior soccer players. Eur J Appl Physiol. 2001; 85(3-4): 240-243, doi: 10.1007/ s004210100468, indexed in Pubmed: 11560076.

11. Latiff S, Bidmos MA, Olateju OI. Morphometric profile of tendocalcaneus of South Africans of European ancestry using a cadaveric approach. Folia Morphol. 2021; 80(1): 196-203, doi: 10.5603/FM.a2020.0026, indexed in Pubmed: 32159844.

12. Malvankar S, Khan WS. Evolution of the Achilles tendon: The athlete's Achilles heel? Foot (Edinb). 2011; 21(4): 193-197, doi: 10.1016/j.foot.2011.08.004, indexed in Pubmed: 21900004.

13. Muraoka T, Muramatsu T, Fukunaga T, et al. Elastic properties of human Achilles tendon are correlated to muscle strength. J Appl Physiol (1985). 2005; 99(2): 665-669, doi: 10.1152/ japplphysiol.00624.2004, indexed in Pubmed: 15790689.

14. O'Brien M. The anatomy of the Achilles tendon. Foot Ankle Clin. 2005; 10(2): 225-238, doi: 10.1016/j. fcl.2005.01.011, indexed in Pubmed: 15922915.

15. Olewnik $Ł$, Gonera B, Kurtys K, et al. A proposal for a new classification of the fibular (lateral) collateral ligament based on morphological variations. Ann Anat. 2019; 222: 1-11, doi: 10.1016/j.aanat.2018.10.009, indexed in Pubmed: 30408521.

16. Olewnik $Ł$, Karauda P, Gonera B, et al. Intramuscular innervation of plantaris muscle evaluated using a modified Sihler's staining protocol - Proposal for a new classification. Ann Anat. 2020; 230: 151504, doi: 10.1016/j. aanat.2020.151504, indexed in Pubmed: 32173561.

17. Olewnik $\measuredangle$, Kurtys K, Gonera B, et al. Proposal for a new classification of plantaris muscle origin and its potential effect on the knee joint. Ann Anat. 2020; 231: 151506, doi: 10.1016/j.aanat.2020.151506, indexed in Pubmed: 32173563.

18. Olewnik $Ł$, Wysiadecki G, Podgórski M, et al. The plantaris muscle tendon and its relationship with the Achilles tendinopathy. Biomed Res Int. 2018; 2018: 9623579, doi: 10.1155/2018/9623579, indexed in Pubmed: 29955614.

19. Olewnik $Ł$, Wysiadecki G, Polguj M, et al. Anatomic study suggests that the morphology of the plantaris tendon may be related to Achilles tendonitis. Surg Radiol Anat. 2017; 39(1): 69-75, doi: 10.1007/s00276-016-1682-1, indexed in Pubmed: 27155667.

20. Olewnik Ł, Zielinska N, Karauda P, et al. A three-headed plantaris muscle: evidence that the plantaris is not a vestigial muscle? Surg Radiol Anat. 2020; 42(10): 1189-1193, doi: 10.1007/ s00276-020-02478-8, indexed in Pubmed: 32382814.

21. Olewnik $t$, Zielinska N, Paulsen $F$, et al. A proposal for a new classification of soleus muscle morphology. Ann Anat. 2020; 232: 151584, doi: 10.1016/j. aanat.2020.151584, indexed in Pubmed: 32810614.

22. Pang BSF, Ying M. Sonographic measurement of achilles tendons in asymptomatic subjects: variation with age, body height, and dominance of ankle. J Ultrasound Med. 2006; 25(10): 1291-1296, doi: 10.7863/ jum.2006.25.10.1291, indexed in Pubmed: 16998101.

23. Park SY, Khemani D, Nelson AD, et al. Rectal gas volume measured by computerized tomography identifies evacuation disorders in patients with constipation. Clin Gastroenterol Hepatol. 2017; 15(4): 543-552.e4, doi: 10.1016/j. cgh.2016.11.013, indexed in Pubmed: 27856363.

24. Patel NN, Labib SA. The achilles tendon in healthy subjects: an anthropometric and ultrasound mapping study. J Foot Ankle Surg. 2018; 57(2): 285-288, doi: 10.1053/j. jfas.2017.10.005, indexed in Pubmed: 29275904.

25. Pichler W, Tesch NP, Grechenig W, et al. Anatomic variations of the musculotendinous junction of the soleus muscle and its clinical implications. Clin Anat. 2007; 20(4): 444-447, doi: 10.1002/ca.20421, indexed in Pubmed: 17022026.

26. Schepsis AA, Jones $H$, Haas AL. Achilles tendon disorders in athletes. Am J Sports Med. 2002; 30(2): 287-305, doi: 10.1177/03635465020300022501, indexed in Pubmed: 11912103

27. Soroceanu A, Sidhwa F, Aarabi S, et al. Surgical versus nonsurgical treatment of acute Achilles tendon rupture: a meta-analysis of randomized trials. J Bone Joint Surg Am. 2012; 94(23): 2136-2143, doi: 10.2106/JBJS.K.00917, indexed in Pubmed: 23224384.

28. Szaro P, Witkowski G, Smigielski R, et al. Fascicles of the adult human Achilles tendon - an anatomical study. Ann Anat. 2009; 191(6): 586-593, doi: 10.1016/j. aanat.2009.07.006, indexed in Pubmed: 19734029.

29. van Dijk CN, van Sterkenburg MN, Wiegerinck Jl, et al. Terminology for Achilles tendon related disorders. Knee Surg Sports Traumatol Arthrosc. 2011; 19(5): 835-841, doi: 10.1007/ s00167-010-1374-z, indexed in Pubmed: 21222102.

30. Weinfeld SB. Achilles tendon disorders. Med Clin North Am. 2014; 98(2): 331-338, doi: 10.1016/j.mcna.2013.11.005, indexed in Pubmed: 24559878.

31. Ying $M$, Yeung $E$, Li B, et al. Sonographic evaluation of the size of achilles tendon: the effect of exercise and dominance of the ankle. Ultrasound Med Biol. 2003; 29(5): 637-642, doi: 10.1016/s0301-5629(03)00008-5. 